\title{
A Case Report of Congenital Afibrinogenemia
}

\section{Aysen Turedi Yıldırım ${ }^{1}$, Gokmen Bilgili ${ }^{2}$, Ozlem Buga ${ }^{3}$, Ozen Tekin ${ }^{3}$, Huseyin Gulen ${ }^{1}$}

\begin{abstract}
Congenital afibrinogenemia is a rare bleeding disorder. It may be manifested as umblical, mucosal, intramuscular, intraarticular, or life-threatening intracranial bleeding. A third-day-old infant was admitted for umblical cord bleeding, and was found to have a prolonged prothrobin time [PT], and activated partial thromboplastin time [aPTT], and a very low fibrinogen level. He was diagnosed as congenital afibrinogenemia, and reported for the rarity of disease, and discussion of novel therapeutic approaches
\end{abstract}

Keywords: Congenital afibrinogenemia, umblical cord bleeding, fibrinogen concentrate

\section{Introduction}

Afibrinogenemia is a very rare bleeding disorder, characterized as a functional disorder of plasma fibrinogen, or its complete absence. Fibrinogen plays a key role in the last step of the coagulation pathway. It is the basic molecule required for the formation of insoluble fibrin clot. Fibrinogen also acts like a bridge between the trombocytes for the formation of thrombocyte clot [1]. Afibrinogenemia is inherited as an autosomal recessive trait, and estimated to have an incidence of 1-2 in a million in the Western world. Its incidence is higher in the Middle East, and in the southern of India, where parental consanguinity is frequent [2]. Uncontrolled umblical bleeding is observed in $85 \%$ of patients, which is a bleeding profile not observed in hemophilia. Ecchymosis, Intra-articular hemorrhage, posttraumatic, or postsurgical bleeding are similar manifestations, as seen in hemophilia patients [3]

\section{Case}

A male infant born at 37 th gestational week to a 22-year-old, healthy, G1P0 woman was admitted to our hospital for jaundice and umblical bleeding. He had ongoing bleeding from the injected site of vitamin $\mathrm{K}$, administered in the hospital of referral. Physical examination also revealed jaundice, but was otherwise unremarkable. Body weight, length, and head circumference were within the normal percentiles for his age. His complete blood count was as follows: hemoglobin: 13.8 $\mathrm{g} / \mathrm{dl}$, leucocyte count: $6830 / \mathrm{mm}^{3}$, trombocyte count: $230,000 / \mathrm{mm}^{3}$; and the peripheral blood smear revealed abundant and clustered trombocytes. The total bilirubin and alanine serum transferase levels were elevated $(17.3 \mathrm{mg} / \mathrm{dl}$, and 143 $\mathrm{U} / \mathrm{L}$, respectively), and the biochemical analysis was otherwise normal. The coagulation profile following vitamin $\mathrm{K}$ administration revealed a prolonged $\mathrm{PT}$ ( $>120$ seconds), and aPTT (>160 second), and a diminished fibrinogen $(<50 \mathrm{mg} / \mathrm{dl})$ level. Diagnosed as congenital afibrinogenemia, fresh frozen plasma (FFP) was commenced (15 $\mathrm{ml} / \mathrm{kg}$ bid $)$,

Received: 25 Jun 2014, Revised 26 Jun 2014, Accepted 28 Jun 2014, Available Online 30 Jun 2014

${ }^{1}$ Celal Bayar University Department of Pediatric Hematology, Manisa-Turkey

${ }^{2}$ Celal Bayar University Department of Neonatology, Manisa-Turkey

${ }^{3}$ Celal Bayar University Department of Pediatrics, Manisa-Turkey

*Corresponding Author: Gokmen Bilgili gokmenbilgili@yahoo.com 
and fibrinogen levels were kept well above $100 \mathrm{mg} / \mathrm{dl}$, controlling umblical bleeding in the first day of treatment. FFP infusions were withheld on the $2^{\text {nd }}$ day; however, on the 7th day following FFP infusions, fibrinogen levels were unmeasurably low, whereas PT and aPTT values were unmeasurably high. The infant was clinically stable, without any signs of bleeding, and was put on a prophylaxis of fibrinogen concentrate $(100 \mathrm{mg} / \mathrm{kg} / \mathrm{dose}$, once 2 weeks), and followed up in the outpatient clinic. Upon absence of any rebleeding episodes at the $3 \mathrm{rd}$ month of the follow-up, the prophylaxis was prolonged to once a month. No complications were observed regarding prophylaxis.

\section{Discussion}

Most common signs of afibrinogenemia include umblical cord bleeding, and bleeding from mucosal surfaces, particularly menorrhagia, epistaxis, and oral mucosal hemorrhage. Musculoskeletal bleeding is reserved for the half of the patients, whereas gastrointestinal and urinary system bleeding account for the less. Intracranial hemorrhage is rare [4]. Bleeding tendency, even among those carrying the same mutation, is quite variable. Yearly hemorrhagic episodes do occur multiply in some, and occassionally in other patients [5]. Reasonable explanations include the presence of yetunidentified modified genes, or coexistence of a thrombophilic disorder [6]. Our patient was admitted for umblical cord bleeding.

Fibrinogen is encoded in the $4 \mathrm{q} 28-\mathrm{q} 31$ by 3 genes, occupying a wide zone of $50 \mathrm{~kb}$, namely the fibrinogen alpha (FGA), beta (FGB), and gamma (FGG). More than 80 mutations in fibrinogen encoding genes have been identified in afibrinogenic, or hypofibrinogenic patients, most $(70 \%)$ being missense mutations. Various specific mutations are relevant to distinct forms of congenital fibrinogen deficiency. Most of the genes involved are those of the FGA gene. Two specific mutations of this gene (FGA IVS4+1G $>$ T c. $510+1 \mathrm{G}>\mathrm{T}$, FGA 11$\mathrm{kb}$ deletion) are more commonly observed in Europeans [7, 8]. The exact diagnosis can be done by identifying the molecular defect. Afibrinogenemia is characterized by the complete absence, or diminished levels of immunoreactive fibrinogen measured by antigenic or functional assays. Coagulation tests, including PT, aPTT, thrombin time, and reptilase time are exceedingly prolonged, and fibrinogen levels cannot be determined by functional, or immunoreactive assays [9]. Gene mutations could not be explored in our patient, however, a diagnosis of congenital afibrinogenemia could be made by showing profoundly prolonged PT, aPTT, and an extremely low fibrinogen level.

Fibrinogen concentrates are available as replacement therapy in afibrinogenemic patients. Virus inactivation, small-volume infusions, and low risk of allergic reaction are their major advantages over other replacement therapies [10]. Cryoprecipitate and FFP shoud be infused only on an emergency basis, when fibrinogen concentrates are unavailable [11]. Unavailability of fibrinogen concentrate on the day of admission in our patient led us to infuse FFP, with resultant control of bleeding without treatment complications.

Thrombotic complications may be observed in afibrinogenemic patients during replacement therapy, such as ischemic feet lesions, ischemic stroke, renal or ovarian vein thrombosis, deep vein thrombosis, and pulmonary emboli $[12,13$, 14, and 15]. Thrombophilic disorders, such as protein $\mathrm{C}$ deficiency may accompany afibrinogenemia, wherein thrombotic tendency is increased by replacement therapy [15]. Primary prophylaxis with fibrinogen concentrates, or cryoprecipitate should be considered in early ages for bleeding prevention [16]. Secondary prophylaxis may be commenced to prevent re-bleeding, particularly following lifethreatening hemorrhages, which commonly consist of weekly infusions. Infusions once 
two weeks, or a month may be applied as well $[17,18]$. Our patient was on primary prophylaxis with fibrinogen concentrates once two weeks, prolonged to once a month upon lack of re-bleeding episodes.

As to sum up, afibrinogenemia is a very rare disorder, manifesting most frequently as umblical cord bleeding during the neonatal period. The most important laboratory findings include prolonged PT, aPTT, and low fibrinogen levels. Fibrinogen levels should be determined in patients with bleeding on admission, when PT and aPTT are found to be prolonged. For the prevention of bleeding episodes, prophylaxis with fibrinogen concentrates may be administered.

\section{References}

1. Bolton-Maggs PH, Perry DJ, Chalmers EA, Parapia LA, Wilde JT, Williams MD, et al. The rare coagulation disorders--review with guidelines for management from the United Kingdom Haemophilia Centre Doctors' Organisation. Haemophilia : the official journal of the World Federation of Hemophilia. 2004;10(5):593-628.

2. Peyvandi F, Duga S, Akhavan S, Mannucci PM. Rare coagulation deficiencies. Haemophilia : the official journal of the World Federation of Hemophilia. 2002;8(3):308-21.

3. Peyvandi F. Results of an international, multicentre pharmacokinetic trial in congenital fibrinogen deficiency. Thrombosis research. 2009;124 Suppl 2:S9-11.

4. Lak M, Keihani M, Elahi F, Peyvandi F, Mannucci PM. Bleeding and thrombosis in 55 patients with inherited afibrinogenaemia. British journal of haematology. 1999;107(1):204-6.

5. Peyvandi F, Haertel S, Knaub S, Mannucci PM. Incidence of bleeding symptoms in 100 patients with inherited afibrinogenemia or hypofibrinogenemia. Journal of thrombosis and haemostasis : JTH. 2006;4(7):1634-7.

6. de Moerloose P, Neerman-Arbez M. Treatment of congenital fibrinogen disorders. Expert opinion on biological therapy. 2008;8(7):979-92.

\section{Conflict of Interest}

The authors declared that they had no conflicts of interest.
7. Neerman-Arbez M, de Moerloose P. Hereditary fibrinogen abnormalities. In: Kaushansky K, Lichtman MA, Beutler E, Kipps TJ, Seligsohn U, Prchal JT, editors. Williams Hematology, 8th ed. New York, NY: McGrawHill. 2010;2051-68.

8. Acharya SS, Dimichele DM. Rare inherited disorders of fibrinogen. Haemophilia : the official journal of the World Federation of Hemophilia. 2008;14(6):1151-8.

9. Peyvandi F. Epidemiology and treatment of congenital fibrinogen deficiency. Thrombosis research. 2012;130 Suppl 2:S7-11.

10. Keeling D, Tait C, Makris M. Guideline on the selection and use of therapeutic products to treat haemophilia and other hereditary bleeding disorders. A United Kingdom Haemophilia Center Doctors' Organisation (UKHCDO) guideline approved by the British Committee for Standards in Haematology. Haemophilia : the official journal of the World Federation of Hemophilia. 2008;14(4):671-84.

11. de Moerloose P, Neerman-Arbez M. Treatment of congenital fibrinogen disorders. Expert opinion on biological therapy. 2008;8(7):979-92.

12. Roque H, Stephenson C, Lee MJ, Funai EF, Popiolek D, Kim E, et al. Pregnancy-related thrombosis in a woman with congenital afibrinogenemia: a report of two successful pregnancies. American journal of hematology. 2004;76(3):267-70. 
13. Haberer JP, Obstler C, Samama CM, Darnige L, Szwebel TA, Meyer A, et al. Postoperative deep venous thrombosis in a woman with congenital afibrinogenaemia treated with fibrinogen concentrates. European journal of anaesthesiology. 2008;25(6):519-21.

14. Cronin C, Fitzpatrick D, Temperley I. Multiple pulmonary emboli in a patient with afibrinogenaemia. Acta haematologica. 1988;79(1):53-4

15. De Mattia D, Regina G, Giordano P, Del Vecchio GC, Altomare M, Schettini F. Association of congenital afibrinogenemia and K-dependent protein C deficiency--a case report. Angiology. 1993;44(9):745-9.
16. de Moerloose P, Neerman-Arbez M. Congenital fibrinogen disorders. Seminars in thrombosis and hemostasis. 2009;35(4):356-66.

17. Peyvandi F, Haertel S, Knaub S, Mannucci PM. Incidence of bleeding symptoms in 100 patients with inherited afibrinogenemia or hypofibrinogenemia. Journal of thrombosis and haemostasis : JTH. 2006;4(7):1634-7.

18. Parameswaran R, Dickinson JP, de Lord S, Keeling DM, Colvin BT. Spontaneous intracranial bleeding in two patients with congenital afibrinogenaemia and the role of replacement therapy. Haemophilia : the official journal of the World Federation of Hemophilia. 2000;6(6):705-8.

Copyright (C) 2014 The Author(s); This is an open-access article distributed under the terms of the Creative Commons Attribution License (http://creativecommons.org/licenses/by/4.0), which permits unrestricted use, distribution, and reproduction in any medium, provided the original work is properly cited. 